\title{
4.6 Особенности разработки маркетинговой стратегии предприятий строительного комплекса
}

В современных экономических условиях для того, чтобы выжить в конкурентной борьбе предприятию необходимо использование стратегических и тактических приемов маркетинга.

Маркетинг в строительстве - отдельный аспект маркетинговой науки, имеющий свои особенности и специфику, которую можно объяснить следующими общими тезисами: жизненный цикл строительного продукта обычно более длительный, чем у других продуктов производственного назначения, а тем более товаров широкого потребления. Процесс разработки маркетинговой стратегии предприятия необходим для детализации выбора стратегии, последовательности ее определения для прежприятия.

На формирование и выполнение маркетинга в сфере строительных услуг влияет ряд внешних и внутренних условий маркетинга в строительстве:

1. Подразделения строительных организаций могут быть достаточно многочисленными и рассредоточенными на обширных территориях. В то же время характер работы многих из них сезонный или временный, что заставляет подразделения и самостоятельные организации быть мобильными, готовыми в сжатые сроки переместить производство на другое место, согласно требованиями заключаемых контрактов.

2. Климатические и природные условия - это те факторы, которые могут существенно снизить скорость выполнения работ и уменьшить вероятность прогнозов о сроках завершения строительства и ввода объектов в эксплуатацию.

3. Технологические процессы как капитального строительства, так и отделочных работ предусматривают большое количество различных их видов.

4. Организация транзакций (рыночного участия) в современных реалиях требует растущих совокупных издержек. 
5. Негативное влияние на результаты строительства оказывает и ряд таких важных факторов, как недостаточное количество оборотных средств, вероятность неравномерного распределения, отсутствие уверенности в платежеспособности заказчиков, а также недостатки и несовершенство в целом системы государственного контроля и регулирования.

В строительной сфере существуют следующие инструменты маркетинга, с помощью которых предприятие может оказывать влияние на рынок, они имеют общее и с продвижением товаров на других рынках:

- качество продукции или услуг;

- ассортиментная и ценовая политика;

- деловая репутация производящей фирмы;

- услуги по доставке товара до потребителя;

- реклама;

- дополнительные сервисные и другие услуги.

Деятельность предприятия в направлении маркетинга целесообразно начинать с планирования. Существуют годовые, долгосрочные и стратегические планы.

Стратегическое планирование - это процесс разработки и реализации стратегии предприятия в будущем на основе прогнозирования изменения параметров внешней среды, определения приоритетных направлений развития и методов эффективного использования стратегических ресурсов. Оно ориентирует на перемены и нововведения, их стимулирование, основано на действиях, опережающих изменения условий окружающей среды, предугадывающих риски и улавливающих возможности ускорения развития предприятия [280, с. 82].

Стратегический план предприятия определяет направления деятельности, которые планирует развивать компания. Затем каждое направление деятельности планируют более подробно. Общая стратегия предприятия и его маркетинговая стратегия во многом совпадают. Маркетинг заботится о потребностях потребителя и о способности компании удовлетворить их; эти же 
факторы определяются миссией и задачами предприятия. В стратегическом планировании предприятия используются многие понятия маркетинга - доля рынка, развитие рынка, рост; иногда бывает сложно отделить стратегическое планирование от маркетингового.

Стратегический план определяет общее предназначение и задачи предприятия [281, с. 35]. В рамках каждого подразделения маркетинг помогает решать общие стратегические задачи.

Разработка маркетинговой стратегии предприятия - это прежде всего процесс создания и практической реализации генеральной программы действий предприятия. Ее цель - эффективное размещение ресурсов для достижения целевого рынка.

Маркетинговая стратегия предприятия означает разработку компонентов, целевых установок, которые влияют на деятельность предприятия в целом. Под этим подразумевается построение структуры целей и определении направлений и инструментария их достижения.

Однако, стоит учесть ряд факторов, которые оказывают влияние на разработку и реализацию маркетинговой стратегии (рис. 1.1).

Стратегия маркетинга основное внимание уделяет целевым покупателям. Компания выбирает рынок, делит его на сегменты, отбирает из них наиболее перспективные и концентрирует свое внимание на обслуживании и удовлетворении этих сегментов. Она разрабатывает маркетинговый комплекс, состоящий из компонентов, находящихся под его контролем: товар (в нашем случае - строительные услуги), цена, сбыт и продвижение товара.

Для составления и приведения в действие оптимального маркетингового комплекса компания производит анализ маркетинговой информации, планирование маркетинга, организацию службы маркетинга и маркетинговый контроль. 


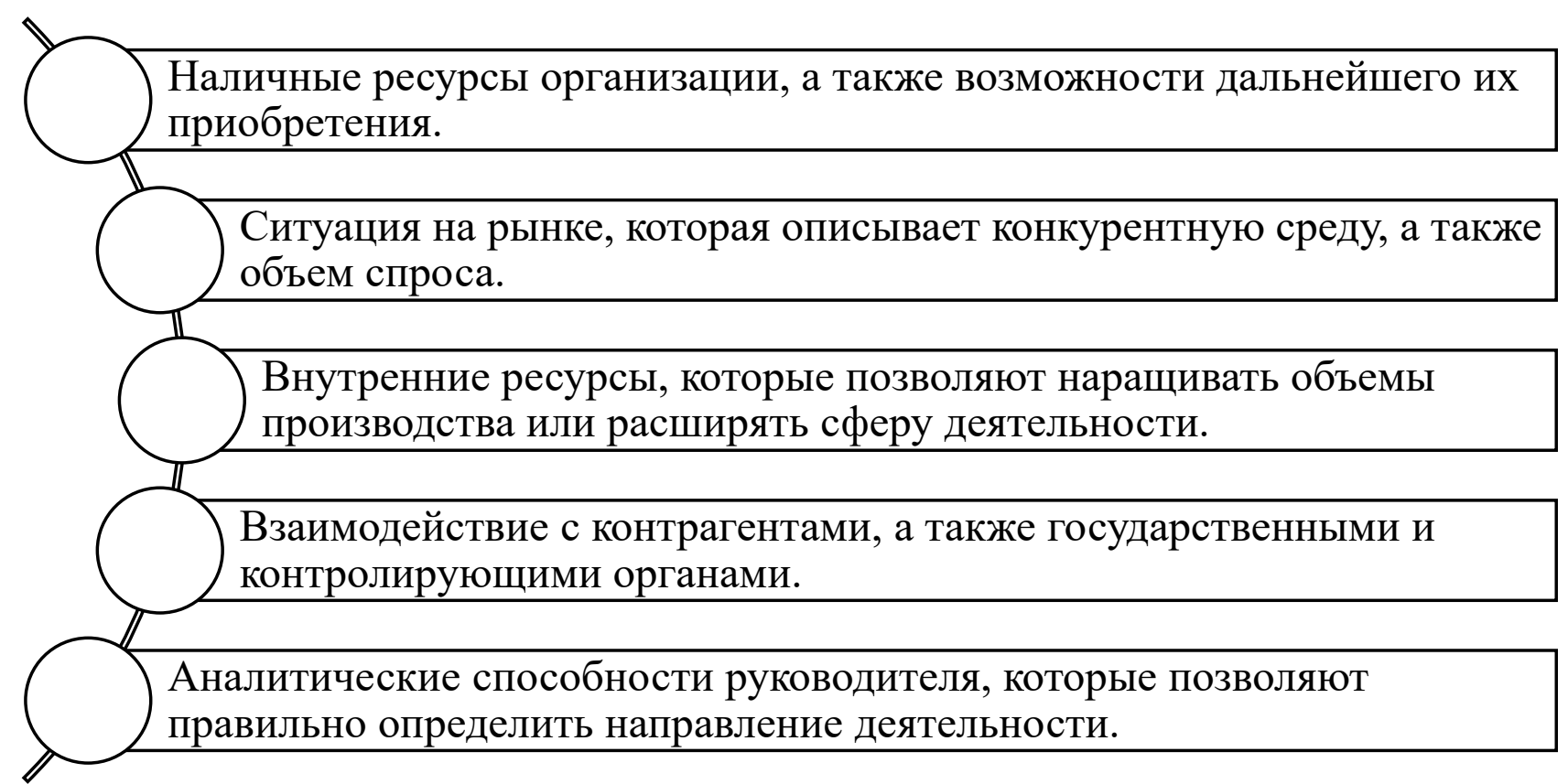

Рис. 1.1 Факторы, влияющие на маркетинговую стратегию

Посредством этих действий компания следит за маркетинговой средой и приспосабливается к ее изменениям.

Для понимания текущего состояния рынка строительное предприятие обязано проводить маркетинговый аудит. Маркетинговый аудит - это систематическое всестороннее изучение деятельности, среды целей и стратегий компании для выявления проблем и возможностей компании.

Факторы макросреды маркетинга строительства можно объединить в следующие группы: демографические, экономические, политические, экологические, научно-технические и культурные факторы.

Самое радикальное влияние на маркетинг строительства оказывает экономическая среда, включающая: общее состояние экономической конъюнктуры; уровень деловой активности в целом и в инвестиционной сфере в частности; степень экономической либерализации и государственного вмешательства в деятельность строительных организаций; открытость экономики иностранным инвесторам и возможности международного обмена; занятость населения и уровень сбережения хозяйств, экономическая политика государства и т.д. 
Основными факторами микросреды маркетинга являются заказчики, поставщики, субподрядчики, конкуренты, коммерческие посредники. В условиях рыночной экономики строительная организация имеет достаточную степень свободы в выборе элементов микросреды маркетинга.

Далее составляется маркетинговая стратегия, используемая для достижения поставленных целей. Маркетинговая стратегия - это логическая схема маркетинговых мероприятий, с помощью которой компания надеется выполнить свои маркетинговые задачи. Она состоит из отдельных стратегий для целевых рынков, позиционирования и маркетингового комплекса. Маркетинговая стратегия должна уточнить сегменты рынка, на которых компания планирует сконцентрировать свои усилия [282, с. 70].

Маркетинговые стратегии предполагают проведение непрерывного системного анализа рыночных потребностей, который будет способствовать разработке тех товаров, которые необходимы конкретным целевым группам. Эти товары обладают особыми свойствами, которые отличают их от продукции конкурентов, и обеспечивают им неоспоримое конкурентное преимущество $[283$, c. 47$]$.

Разработка алгоритма формирования и реализации маркетинговой стратегии предприятия способствует снижению трудоемкости процесса маркетингового планирования, повышению стабильности развития предприятия в условиях усиления конкуренции и высокой динамики рыночной конъюнктуры [284, с. 185].

Процесс разработки маркетинговой стратегии является важнейшим направлением при ведении бизнеса. Разработка маркетинговой стратегии способствует эффективному управлению деятельностью предприятия [285, с. 781].

При формировании маркетинговых стратегий целесообразно исходить из оценки основных рыночно-экономических факторов и анализа существующего стратегического потенциала. Цель разработки стратегии - определение 
основных приоритетных направлений и пропорций развития предприятия с учетом материальных источников его обеспечения и спроса рынка [286, с. 137].

Этапы разработки маркетинговой стратегии предприятий строительного комплекса включают:

Этап 1. Происходит оценка настоящего состояния рынка. На этом этапе необходимо дать экспертную оценку доли рынка, провести анализ реализации услуг и установить, от чего зависит спрос - от сезонного спроса или прихода и переработки сырья. Определить, каким образом, рынок данного вида товара или услуг изменится и не произойдут ли существенные изменения.

Этап 2. Происходит сегментация рынка и определяется потребительский спрос. Выбор целевого сегмента осуществляют для понимания для удовлетворения каких потребностей нацелено предприятие, какие товары и услуги они будут предоставлять потребителям. Для более удачной работы компании на рынке ему нужно сосредоточиться на нишах рынка, также на тех нуждах потребителей, которые до сих пор не удовлетворены.

Этап 3. Проводится анализ конкурентов и определяется конкурентоспособность предприятия (если речь не идет о монополистах). Необходимо определить, чем предприятие отличается от всех других, т.е. слабые стороны.

Этап 4. Проходит формирование целей маркетингового развития, определение четких целей помогает и позволяет трансформировать миссию предприятия в конкретные действия. Цели могут быть такими: увеличение объема продаж, извлечение прибыли, удовлетворение общественного мнения, формирование имиджа предприятия.

Этап 5. Проводится исследование возможных альтернатив в плане стратегии. Определяются дополнительные варианты развития предприятия [287, c. 665$]$.

Этап 6. Происходит создание определенного имиджа предприятия на рынке. 
Этап 7. Производится оценка стратегии с точки зрения ее финансовой состоятельности, на этом этапе проводятся: анализ и прогнозирование качества и ресурсоемкости будущих продуктов или услуг; прогнозирование конкурентоспособности имеющихся и будущих продуктов, услуг предприятия; прогнозирование объемов выручки и прибыли; определение контрольных показателей и промежуточных этапов контроля (сроки и контрольные значения).

Иногда разработанную стратегию приходится корректировать или полностью изменять. Это происходит при резком изменении рыночной ситуации (при появлении на рынке более конкурентоспособной продукции или услуг).

Разработка маркетинговой стратегии позволяет предприятию: значительно расширить количество потребителей и увеличить объем продаж товаров и услуг; повысить конкурентоспособность товаров и услуг; создать инструмент массового привлечения потребителей; выбрать эффективную ценовую и продуктовую политику; создать механизм контроля.

Маркетинговая стратегия строительного предприятия является основой и служит ориентиром для всех строительных планов организации и занимает центральное место в системе планов. Такие программы позволяют предприятию правильно оценить свои возможности, недостатки и отличия от конкурентов, оценить финансовые средства, материальные ресурсы, нематериальные активы.

Таким образом, под маркетинговой стратегией понимают план действий по увеличению прибыли предприятия. Для предприятия маркетинговая стратегия является основополагающей стратегией его развития, которая включает в себя пошаговую инструкцию по достижению поставленных целей, с прогнозированием в среднем на год или любой иной заданный период времени. 